\title{
Research on flexibility analysis of integrated energy system
}

\author{
Xie Han ${ }^{1}$, Li Qifen ${ }^{1, *}$, Yang Yongwen ${ }^{1}$, Song Lifei ${ }^{1}$, Ning Ning ${ }^{1}$, Jiang Xiumei ${ }^{1}$ \\ ${ }^{1}$ College of Energy and Mechanical Engineering, Shanghai University of Electric Power, Shanghai 200090, China
}

\begin{abstract}
Regarding the research on the flexibility of the integrated energy system, firstly, this paper explains the necessity of flexibility for the development of the integrated energy system, and analyses the features of flexibility including the characteristics, the role, and the quantitative factors, which provides a basis for research on flexibility of integrated energy systems. Based on the above characteristics, this article explores the resources that can provide system flexibility in all aspects of the integrated energy system "source-network-load-storage", and analyzes and evaluates their flexibility.
\end{abstract}

\section{Introduction}

Under the dual pressure of energy security and resource shortages, it has become the consensus of governments of all countries to promote the joint supply of multiple energy sources and improve the flexibility between systems. The demand proposal and development of energy internet and integrated energy system (IES) research embodies the profound background demands of many driving forces such as environment, economy, society, technology and policy [1]. Faced with the closer coupling of various energy sources in the integrated energy system and the more frequent interactions between different energy systems, it is urgent to find a unified model that can describe such a complex system to reflect the various aspects of the integrated energy system in "source-network-load" impacting on the system and the dynamic balance them, which can better play the role of multi-energy complementation, coordination and optimization of the integrated energy system.

For the integrated energy system, the penetration rate of renewable energy is further increased, higher than that of the general energy supply system, and the source-side energy supply equipment is more diversified, which increases the imbalance between supply and demand of the system and some uncertain factors. The demand is even more urgent. For example, after the proportion of renewable energy increases, the characteristics of volatility, un-certainty and load independence of its output will be am-plified. The actual system may bring the following 4 spe-cific problems: 1.The frequency adjustment requirements are more frequent, because the renewable energy increa-ses the short-term net load change; 2 . The renewable en-ergy output changes so that it matches the load The out-put of the unit should also be increased or decreased accordingly, making the unit's large-scale climbs and landslides appear more frequently, and higher requrements for the system's climbing and landslide capa-bilities; 3. The net result of the uncertainty of resources such as wind and sunlight Increased load volatility; 4. Expanded the output range of the entire system (no longer the maximum and minimum user load), the reduction of the user's minimum load will reduce the output of the base load unit, when the load is low, the net When the load drops sharply, there may be an oversupply of power supply, which may result in abandonment of wind and electricity or shutdown of units. Therefore, the demand for flexibility of the integrated energy system is more urgent and the capacity for flexibility is greater. It is necessary to allocate more flexible resources or tap the flexibility potential from existing resources.

\section{Characteristic analysis of flexibility of integrated energy system}

\subsection{Features of system flexibility}

1.Inherent characteristics: When the system is determined, its flexibility is also determined. For any integrated energy system, it has an inherent tolerance, allowing the system to deviate from the preset operating point or in a critical stable state within a certain degree or time, without causing the system to quickly collapse. Tolerance can be considered the inherent flexibility of the system.

2. Time scale: Generally speaking, the supply and demand imbalance caused by uncertainty factors will last for a period of time, which is the time scale of flexibility demand. For flexibility resources, the adjustment of output must be completed within the limit of this time scale, and the output time must be guaranteed until the imbalance problem is solved. Generally speaking, the time scale can be set as $1 \mathrm{~min}, 10 \mathrm{~min}$ and $15 \mathrm{~min}$, but generally speaking, it should not exceed $30 \mathrm{~min}$.

\footnotetext{
* Corresponding author: liqifen@shiep.edu.cn.
} 


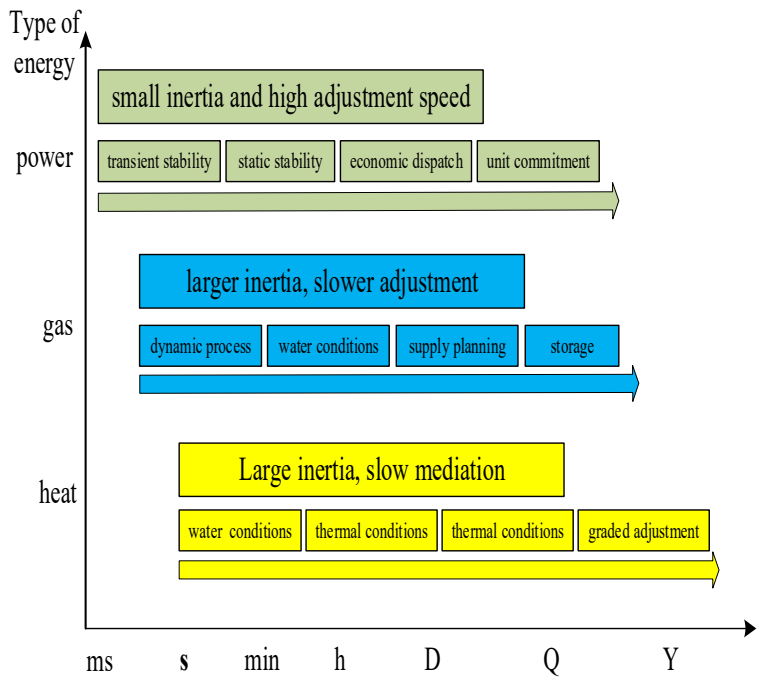

Fig.1. Schematic diagram of multiple time scales

Due to the unified and integrated supply of multiple energy sources, the difference in the balance speed and response speed of different energy sources will also cause the integrated energy system to have multiple time scales in the adjustment balance. As shown in Figure 1, the inertia of the power system is the smallest and the adjustment speed is fast; the natural gas system is second; the thermal system is second. Therefore, the adjustment of system flexibility requires in-depth study of the time scale relationship between different energy flows, and then proposes the time scales are matched with the best energy management methods to improve the safety and flexibility of the energy supply system.

3.Directionality: When there is an imbalance between supply and demand in the system, there will be a directional problem, which corresponds to the flexibility resource. The essence is whether the output of the flexibility resource should be adjusted upward or downward, that is, the resource called Is it an upward flexibility resource or a downward flexibility resource.

\subsection{The role of system flexibility}

1. Frequency modulation: the real-time difference between the actual net load of the output and the predicted net load, and the user ensures the frequency is stable. To ensure the system output and load balance, and maintain the safe operation of the system. The frequency service has certain requirements on the response rate of the provider, and usually requires the response required by the AGC signal to be completed within a few seconds, which is generally provided by a traditional generator set. But energy storage, large-scale wind power, and electric vehicles also have frequency modulation capabilities.

2. Operational reserve: refers to the active power capacity prepared for anticipated accidents such as equipment failures, operating fluctuations, and line interruptions, so it is also called contingency reserve. According to whether the unit is on, the operating reserve can be divided into spinning reserve and nonspinning reserve. Running standby needs to respond to instructions within 30 minutes to ensure the system's supply and demand balance. In addition to traditional generator sets, resources such as energy storage, electric vehicles, and interruptible loads can also provide operational backup.

3. Flexible adjustment of the system's real-time operation: to meet the net load changes in real-time scheduling, and to consider the volatility and uncertainty of net load. Any resource that can be scheduled in real time can be provided, and its capacity and adjustment speed determine the number of products it can provide ${ }^{[5]}$.

\subsection{Quantitative factors of system flexibility}

The physical dimensions to quantify the flexibility of the system mainly include the following dimensions: climbing rate $\rho$, power $\mathrm{P}$ and capacity $\varepsilon$, and there is an obvious mathematical relationship between the three index parameters: climbing speed is the derivative of power, and power is capacity Derivatives, the three constitute a three-dimensional system of system flexibility.

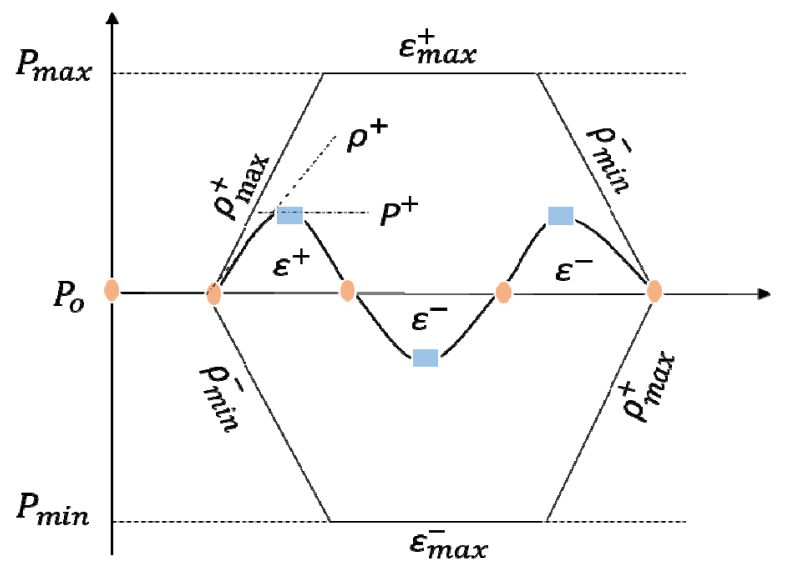

Fig.2. Schematic diagram of the relationship between flexibility metrics

As shown in Figure 2, each has a specific meaning to the system. The ramp rate determines the speed of response, the primary factor considered when the system is adjusted quickly; power determines The instantaneous energy that can be provided to the system at this moment is the most direct compensation measure when the system has an imbalance in power supply and demand; the capacity determines the energy that can be fed back to or absorbed from the system within a period of time, that is, during the adjustment period. Implement the entire adjustment process.

\section{Flexibility resource analysis}

\section{1"Source" side: energy supply side}

Any part that can provide energy demand can be used as the source side of the energy supply system. It is the main provider of flexible resources, and its energy supply capacity often directly determines the ability of upward 
Table1. Characteristics of typical power flexibility Comparative

\begin{tabular}{|c|c|c|c|c|}
\hline Kinds & $\begin{array}{l}\text { Minimum load } \\
\text { [\% P rated] }\end{array}$ & $\begin{array}{l}\text { Climbing rate } \\
{[\% \mathrm{P} \text { rated } / \mathrm{min}]}\end{array}$ & Start Time & Response time \\
\hline Lignite power plant & $35 \sim 60 \%$ & $1 \sim 6 \%$ & $\begin{array}{c}\text { Cold: } 3-10 \mathrm{~h} \\
\text { Heat: } 1.25-6 \mathrm{~h}\end{array}$ & \multirow{2}{*}{$\begin{array}{l}15 \mathrm{~s}(75 \% \mathrm{P} \text { rated }) \\
30 \mathrm{~s}(90 \% \mathrm{P} \text { rated })\end{array}$} \\
\hline Hard coal power plant & $25 \sim 40 \%$ & $1.5 \sim 6 \%$ & $\begin{array}{l}\text { Cold: } 1.5-4 \mathrm{~h} \\
\text { Heat: } 5-10 \mathrm{~h}\end{array}$ & \\
\hline CCGT(600MW) & $40 \%$ & $4-8 \%$ & Heat: $1 \mathrm{~h}$ & \multirow{4}{*}{$<10$ s } \\
\hline OCGT 9E.03-132MW & $35 \%$ & $50 \mathrm{MW} / \mathrm{min}$ & $\begin{array}{l}\text { Regular: } 30 \mathrm{~min} \\
\text { Peak: } 10 \mathrm{~min}\end{array}$ & \\
\hline $\begin{array}{l}\text { CCGT(Uniaxial )9E.03- } \\
\text { 201MW }\end{array}$ & $46 \%$ & $50 \mathrm{MW} / \mathrm{min}$ & Heat: $38 \mathrm{~min}$ & \\
\hline $\begin{array}{c}\text { CCGT(Biaxial)9E.03- } \\
\text { 405MW }\end{array}$ & $22 \%$ & $100 \mathrm{MW} / \mathrm{min}$ & Heat: $38 \mathrm{~min}$ & \\
\hline
\end{tabular}

Table2. Comparative analysis of various typical energy storage

\begin{tabular}{|c|c|c|c|c|c|}
\hline $\begin{array}{c}\text { Energy } \\
\text { storage } \\
\text { method }\end{array}$ & capacity /GW·h & Response time & effectiveness $/ \%$ & investment /(USD/kW.h) & life /a \\
\hline $\begin{array}{c}\text { Battery } \\
\text { storage }\end{array}$ & $<0.2$ & $<1 \mathrm{~s}$ & $70-90$ & $85-4800$ & $20 \sim 30$ \\
\hline $\begin{array}{c}\text { Pumped } \\
\text { storage }\end{array}$ & $>2$ & $10 \mathrm{~s}-40 \mathrm{~min}$ & 87 & $45-85$ & 40 \\
\hline $\begin{array}{c}\text { Flywheel } \\
\text { energy }\end{array}$ & $<0.5$ & $<1 \mathrm{~s}$ & $90-93$ & $170-420$ & $20 \sim 30$ \\
\hline $\begin{array}{c}\text { Compressed } \\
\text { air energy }\end{array}$ & $<100$ & $1-10 \mathrm{~min}$ & 80 & $12-85$ & 30 \\
\hline
\end{tabular}

Table3. Comparative analysis of flexibility of various typical loads

\begin{tabular}{|c|c|c|c|c|c|}
\hline Load type & $\begin{array}{c}\text { Timeliness of } \\
\text { regulation }\end{array}$ & $\begin{array}{c}\text { Adjustable } \\
\text { range }\end{array}$ & $\begin{array}{c}\text { Adjustable } \\
\text { speed }\end{array}$ & Translatable & Economy \\
\hline Industrial load & good & high & fast & general & poor \\
\hline Commercial load & better & general & slow & general & better \\
\hline Agricultural load & general & low & fast & poor & good \\
\hline Residential load & poor & low & slow & poor & poor \\
\hline
\end{tabular}

and downward flexible adjustment and the quality of adjustment. The flexibility of the source side is mainly divided into two types: the adjustment flexibility of the energy supply and the ability to participate in frequency modulation. The first type mainly uses the adjustable capacity (upward and downward) of the source side system or equipment, the climbing speed, The second type is mainly related to the response speed and the degree of adjustment. The details are as follows.

Comparison and analysis of various source-side typical units and the flexibility characteristics of their energy supply power:

\section{2"Network" side: Energy transmission side}

The flexibility of the network side mainly includes two aspects: 1. It mainly utilizes the transmission characteristics of the network to coordinate in different space ranges and different time scales to achieve the purpose of flexible adjustment; 2 . Use the thermal inertia and storage characteristics of the pipeline, Maintain the balance of energy supply and demand for a period of time to release system capacity and increase adjustment flexibility. There are five main scheduling methods that can provide flexibility:
1. Multi-level two-way coordinated scheduling;

2. Multi-time scale scheduling transaction;

3. Multi-functional and complementary scheduling transactions;

4. Micro-balance scheduling of centralized optimization and decentralized optimization;

5. Multi-energy convergence and interconnection network.

\section{3 "Storage" side: Energy storage side}

Energy storage can be divided into electricity storage, heat storage, cold storage, and gas storage according to the type of energy; electricity storage can be mainly divided into chemical energy storage, mechanical energy storage, electromagnetic energy storage, and heat and cold storage can be divided into phaseless Variable energy storage and phase change energy storage. Gas storage is mainly pipeline storage and container tank storage. Each type of energy storage has its own characteristics. It lists different energy storage methods and analyzes and compares their performance. The main influencing factors are: storage-discharge efficiency, life requirements, adjustable capacity, translatability, Economic efficiency, among which, due to the large 
number of types of lithium batteries and the large difference in performance, the various types of lithium battery packs are separately analyzed, and the content is as follows.

In addition to the electricity storage described in detail above, energy storage also includes cold storage, heat storage, gas storage, etc. The specific energy storage methods and performance are shown in the following table analysis.

\section{4 "Load" side: energy demand side}

The scientific management and intelligent control of the load side play a key role in the efficient and economical operation of the energy system. Nowadays, there has been a certain amount of research and operation on the hierarchical control and integrated dispatching of the load side, which are shown in the following aspects :

1. Virtual power plant technology;

2. Load-side demand response technology;

3. Utilization of building heating and cooling thermal inertia;

4. Utilization of temperature difference and pressure difference during use of LNG, steam, etc.

Among them, the application of load-side demand response technology needs to be based on the classification of load-side users and the full investigation and understanding of the user load curve after classification. According to the types of users, this paper divides users into four types: industrial load, commercial load, residential electricity load, and agricultural load, and compares the performance of flexible adjustment of these four types of load.

\section{Conclusions}

This article studies the flexibility of the integrated energy system from the perspectives of its characteristics, functions, and quantitative factors, and explores the resources that can provide system flexibility in all aspects of the integrated energy system "source-networkload-storage". It also analyzes and evaluates its activity capacity, which provides a way of thinking and foundation for further research on the flexibility of the integrated energy system. In addition, the basic characteristics of flexible resources and their respective application scenarios are analyzed, and the basic position of system flexibility in the operation of integrated energy systems is clarified.

\section{Acknowledgments}

Science and Technology Innovation Project of Shanghai Science and Technology Committee (18DZ1203403 和 18DZ1203304).

\section{References}

1. Jia Hongjie, Mu Yunfei, Yu Xiaodan. Thinking on the development of my country's integrated energy
system[J].ElectricPowerConstruction,2015,36(01):1 6-25.

2.Lu Zongxiang, Li Haibo, Qiao Ying. Flexibility Planning and Challenges of Power System Containing High Proportion of Renewable Energy[J].Automation of Electric Power Systems,2016,40(13):147-158.

3.LANNOYE E , FLYNN D , O'MALLEY $M$. Evaluation of power system flexibility J] . IEEE Transactions on Pow er Systems, 2012, 27( 2): 922-931 .

4.WANG Q, HODGE B M. Enhancing power system operational flexibility with flexible ramping products: A review [J].IEEE Transactions on Industrial Informatics, 2017, 13(4) : 1652-1664 .

5.Xiao Dingyao. Research on flexibility evaluation index and optimization of power system with large-scale renewable energy [D]. Shanghai Jiaotong University, 2015. 